\title{
Presepsis Depressive Symptoms Are Associated with Incident Cognitive Impairment in Survivors of Severe Sepsis: A Prospective Cohort Study of Older Americans
}

\author{
Dimitry S. Davydow, MD, MPH, * Catherine L. Hough, MD, MSc, ${ }^{\dagger}$ Kenneth M. Langa, MD, \\ $\mathrm{PhD},{ }^{+\$ \pi}$ and Theodore J. Iwashyna, MD, PhD
}

OBJECTIVES: To test the hypothesis that presepsis depressive symptoms are associated with risk of new cognitive impairment in survivors of severe sepsis.

DESIGN: Prospective longitudinal cohort study.

SETTING: Population-based cohort of older U.S. adults interviewed as part of the Health and Retirement Study (1998-2006).

PARTICIPANTS: Four hundred forty-seven individuals with normal presepsis cognition who survived 540 hospitalizations for severe sepsis and completed at least one follow-up interview.

MEASUREMENTS: Severe sepsis was identified using a validated algorithm in Medicare claims. Depressive symptoms were assessed prospectively using a modified version of the Center for Epidemiologic Studies Depression Scale. Cognitive function was assessed using versions of the Telephone Interview for Cognitive Status (TICS). Logistic regression with robust standard errors was used to examine associations between substantial depressive symptoms at any interview before sepsis and incident cognitive impairment (mild or moderate to severe cognitive impairment) at any interview after sepsis.

RESULTS: The prevalence of substantial depressive symptoms in participants with normal cognition before sepsis was $38 \%(95 \%$ confidence interval $(\mathrm{CI})=34-42 \%)$. After severe sepsis, $18 \%(95 \% \mathrm{CI}=15-20 \%)$ of survivors had incident cognitive impairment. In unadjusted analyses, presepsis substantial depressive symptoms were associated with postsepsis incident cognitive impairment (odds ratio

From the *Department of Psychiatry and Behavioral Sciences, 'Department of Medicine, School of Medicine, University of Washington, Seattle, Washington; ${ }^{\ddagger}$ Department of Internal Medicine, ${ }^{8}$ Institute for Social Research, University of Michigan, and "Center for Clinical Management Research, Ann Arbor Veterans Affairs, Ann Arbor, Michigan.

Address correspondence to Dimitry S. Davydow, Department of Psychiatry and Behavioral Sciences, University of Washington School of Medicine, Box 359911, Harborview Medical Center, 325 Ninth Ave, Seattle, WA 98104. E-mail: ddavydo1@u.washington.edu

DOI: 10.1111 /jgs.12001
$(\mathrm{OR})=2.56,95 \% \mathrm{CI}=1.53-4.27)$. After adjustment for demographics, health-risk behaviors, clinical characteristics of the sepsis episode, and presepsis TICS scores, substantial presepsis depressive symptoms remained the strongest factor associated with postsepsis incident cognitive impairment $(\mathrm{OR}=2.58,95 \% \mathrm{CI}=1.45-4.59)$.

CONCLUSION: Substantial presepsis depressive symptoms are independently associated with incident postsepsis cognitive impairment. Depressed older adults may be particularly at risk of developing cognitive impairment after a serious medical illness. J Am Geriatr Soc 60:22902296, 2012.

Key words: depression; sepsis; cognition; outcome assessment (health care)

$\mathrm{C}$ ognitive impairment is a serious public health problem in light of the aging of the population. Cognitively impaired older adults are at greater risk of mortality. ${ }^{1}$ Furthermore, cognitive impairment is associated with higher healthcare costs, with disproportionate burdens on Medicare and Medicaid ${ }^{2,3}$ and on families and informal caregivers. ${ }^{4}$ Millions of Americans survive critical illnesses annually, ${ }^{5}$ and more than half are aged 65 and older. ${ }^{6}$ Emerging evidence suggests that older adults are at greater risk of developing cognitive impairment after critical illnesses. ${ }^{3,6}$ In particular, severe sepsis, which has been called the "quintessential disease of the aged," ${ }^{7}$ is the most common noncardiac cause of critical illness ${ }^{8}$ and has been shown to be independently associated with substantial, persistent cognitive impairment in survivors, ${ }^{3,9}$ yet it is unknown which individuals with severe sepsis are at greatest risk of becoming cognitively impaired.

A growing body of research has found that latelife depression is associated with risk of dementia. ${ }^{10-12}$ 
Studies have found an association between depression and cognitive decline in carriers of the APOE $\varepsilon 4$ allele, a genetic marker for Alzheimer's disease. ${ }^{13,14}$ Depression may also increase the risk of cognitive impairment because of behavioral factors such as smoking, sedentary lifestyle, and poor adherence to treatment of chronic medical conditions. ${ }^{12}$ Depression, cognitive impairment, and sepsis are all associated with higher levels of proinflammatory markers, ${ }^{11,12,15}$ suggesting plausible physiological and behavioral links between depression and cognitive impairment in the aftermath of severe sepsis.

The present study used an ongoing longitudinal cohort of older Americans to test the hypothesis that presepsis depressive symptoms are associated with risk of incident cognitive impairment in survivors of severe sepsis.

\section{METHODS}

\section{Study Population}

The study cohort was from the Health and Retirement Study (HRS), a longitudinal investigation of communitydwelling U.S. adults aged 50 and older. Details of the HRS have been described previously. ${ }^{3}$ The University of Michigan institutional review board approved the HRS protocol.

All HRS respondents with at least one interview from 1998 to 2004 who were not cognitively impaired, who had Medicare claims-based data for a subsequent hospitalization for severe sepsis from 1998 to 2005, and who had at least one depression assessment before sepsis were studied. All participants were followed up through death or the 2006 interview. The analyses focused on severe sepsis hospitalizations that participants survived long enough afterwards to complete at least one interview.

\section{Demographic and Clinical Characteristics}

Data were obtained on demographic characteristics (age, race and ethnicity, sex, education, and marital status) and health-risk behaviors (alcohol use and smoking) from the HRS interviews.

Information on baseline comorbidity (Charlson comorbidity score $)^{16}$ and severe sepsis-related clinical characteristics was abstracted from the Medicare claims, including an organ dysfunction score (the sum of the number of organ failures of cardiovascular, neurological, hematological, hepatic, renal, or respiratory origin); $; 3$ hospital length of stay; intensive care unit admission; and requirements for mechanical ventilation, major surgery, and dialysis.

\section{Definition of Severe Sepsis}

A validated and widely used claims-based definition of severe sepsis was used. ${ }^{7,17,18}$ The definition requires evidence of a concomitant infection and new-onset organ dysfunction during the same hospitalization, consistent with the international consensus conference definitions of severe sepsis. ${ }^{17}$

\section{Exposure of Interest}

The exposure of interest was the presence of presepsis substantial depressive symptoms. The HRS assessed depression at each wave using an eight-item version of the Center for Epidemiologic Studies Depression Scale (CES-D).${ }^{19}$ Prior studies have reported that this modified version loses little of the structure and precision of the original scale..$^{20,21}$ The current study used a score of 4 or higher to define substantial depressive symptoms at any interview before severe sepsis because HRS investigators estimated that this threshold was comparable with a score of 16 or higher on the full CES-D. ${ }^{22}$

\section{Outcomes of Interest}

The primary outcome was incident cognitive impairment (mild or moderate to severe) found at any HRS interview after severe sepsis. The HRS assessed cognitive impairment in self-respondents using two modified versions of the Telephone Interview for Cognitive Status (TICS) during biennial interviews. ${ }^{3}$ Respondents aged 65 and older were administered a 35-point test that included tests of memory, serial 7 subtractions, naming, and orientation. Selfrespondents younger than 65 were administered a morelimited 27-point scale test which excluded the orientation items. Thresholds on the cognitive assessments for normal cognitive functioning and mild and moderate to severe cognitive impairment were defined based on prior HRS studies. $^{3,23}$

To identify incident cognitive impairment after a hospitalization for severe sepsis, all individuals found to have mild or moderate to severe cognitive impairment at any HRS interview before sepsis were excluded. Previous examination has identified that individuals with mild and moderate to severe cognitive impairment have a level of cognitive dysfunction consistent with a diagnosis of dementia and an average of 1.1 and 2.5 limitations, respectively, in instrumental activities of daily living. ${ }^{23}$

In addition to the primary analysis of interest, whether the association differed between presepsis substantial depressive symptoms and new postsepsis mild cognitive impairment or new postsepsis moderate to severe cognitive impairment was also separately examined.

\section{Statistical Analysis}

The unit of analysis for all analyses was the hospitalization. All descriptive statistics are presented as means and standard deviations (SDs) or medians and interquartile ranges (IQRs) for continuous variables and as percentages for proportions. Univariate analyses examining the association between participant baseline and severe sepsis episoderelated characteristics and presepsis substantial depressive symptom status were conducted using one-way analysis of variance for continuous variables and chi-square or Fisher exact tests for categorical variables.

To examine whether presepsis substantial depressive symptoms were associated with incident cognitive impairment (mild or moderate to severe) postsepsis, logistic regression models with robust error variances were used to account for participants who had more than one distinct hospitalization for severe sepsis. ${ }^{24}$ After an initial unadjusted regression, three groups of potential confounding variables chosen a priori that have been found to be important in cognitive impairment and general medical 
Table 1. Participant and Clinical Characteristics of Hospitalizations for Severe Sepsis According to Presepsis Depression Status

\begin{tabular}{|c|c|c|c|c|}
\hline Characteristic & Total, $\mathrm{N}=517^{\mathrm{a}}$ & $\begin{array}{c}\text { Substantial Depressive } \\
\text { Symptoms at Any Interview } \\
\text { Before Sepsis, } n=195\end{array}$ & $\begin{array}{l}\text { Without Substantial } \\
\text { Depressive } \\
\text { Symptoms, } n=322\end{array}$ & $\begin{array}{c}\text { Test Statistics Comparing } \\
\text { Participants with and without } \\
\text { Substantial Depressive Symptoms }\end{array}$ \\
\hline Age, mean $\pm S D$ & $76.1 \pm 8.5$ & $75.1 \pm 8.5$ & $76.8 \pm 8.4$ & $F=4.63^{c}$ \\
\hline Female, $\mathrm{n}(\%)$ & $282(54.5)$ & $121(62.1)$ & $161(50.0)$ & $\chi^{2}=7.11^{d}$ \\
\hline \multicolumn{5}{|l|}{ Race, n (\%) } \\
\hline Other & $6(1.2)$ & $2(1.0)$ & $4(1.2)$ & \\
\hline \multicolumn{5}{|l|}{ Education, n (\%) } \\
\hline$\leq$ High school & $199(38.5)$ & $94(48.2)$ & $105(32.6)$ & $\chi^{2}=27.92^{\mathrm{e}}$ \\
\hline Some college & $180(34.8)$ & $74(37.9)$ & $106(32.9)$ & \\
\hline College graduate & $138(26.7)$ & 27 (13.8) & $111(34.5)$ & \\
\hline \multicolumn{5}{|l|}{ Living arrangement, $\mathrm{n}(\%)$} \\
\hline $\begin{array}{l}\text { Unmarried and } \\
\text { living alone }\end{array}$ & $150(29.1)$ & $56(28.9)$ & $94(29.2)$ & \\
\hline $\begin{array}{l}\text { Alcohol use, d/wk, } \\
\text { mean } \pm \text { SD }\end{array}$ & $1.6 \pm 1.1$ & $1.3 \pm 0.8$ & $1.7 \pm 1.2$ & $F=18.70^{\mathrm{e}}$ \\
\hline \multicolumn{5}{|l|}{ Smoking status, n (\%) } \\
\hline Never smoked & $170(32.9)$ & $63(32.3)$ & $107(33.2)$ & $\chi^{2}=0.07$ \\
\hline Former smoker & $277(53.6)$ & $106(54.4)$ & $171(53.1)$ & \\
\hline Current smoker & $70(13.5)$ & $26(13.3)$ & $44(13.7)$ & \\
\hline $\begin{array}{l}\text { Charlson comorbidity } \\
\text { score, mean } \pm \text { SD }\end{array}$ & $1.9 \pm 1.5$ & $2.1 \pm 1.6$ & $1.7 \pm 1.4$ & $F=9.15^{d}$ \\
\hline \multicolumn{5}{|c|}{ Panel B: Characteristics of the severe sepsis hospitalization } \\
\hline $\begin{array}{l}\text { Organ dysfunction score, } \\
\text { mean } \pm \text { SD }\end{array}$ & $1.2 \pm 0.4$ & $1.2 \pm 0.4$ & $1.2 \pm 0.4$ & $F=0.05$ \\
\hline $\begin{array}{l}\text { Admitted to an intensive } \\
\text { care unit, } \mathrm{n}(\%)\end{array}$ & $226(43.7)$ & $76(39.0)$ & $150(46.6)$ & $\chi^{2}=2.86$ \\
\hline $\begin{array}{l}\text { Required mechanical } \\
\text { ventilation, } \mathrm{n}(\%)\end{array}$ & $105(20.3)$ & $39(20.0)$ & $66(20.5)$ & $\chi^{2}=.02$ \\
\hline $\begin{array}{l}\text { Required major } \\
\text { surgery, } \mathrm{n}(\%)\end{array}$ & $113(21.9)$ & $35(17.9)$ & $78(24.2)$ & $\chi^{2}=2.80$ \\
\hline Required dialysis, $\mathrm{n}(\%)$ & $21(4.1)$ & $11(5.6)$ & $10(3.1)$ & $\chi^{2}=2.00$ \\
\hline $\begin{array}{l}\text { Hospital length of stay, } \\
\text { days, mean } \pm S D\end{array}$ & $10.9 \pm 10.3$ & $10.5 \pm 7.9$ & $11.2 \pm 11.6$ & $\tilde{F}=.61$ \\
\hline
\end{tabular}

a 24 hospitalizations $(4 \%)$ were missing from presepsis depressive symptom data.

${ }^{\mathrm{b}} F$-statistic with 516 degrees of freedom, Pearson chi-square $\left(\chi^{2}\right)$ with 2 degrees of freedom, or Fisher exact $P$-value.

${ }^{\mathrm{c}} P<.05$.

${ }^{\mathrm{d}} \mathrm{P}<.01$.

${ }^{\mathrm{e}} P<.001$.

$\mathrm{SD}=$ standard deviation.

and critical illness-related research were then added; $3,7,12$ demographic characteristics (age, sex, race, education, marital status), health risk behaviors (alcohol use and smoking) and chronic medical comorbidity (Charlson score), and severe sepsis episode characteristics (organ dysfunction score, length of stay, intensive care unit admission, mechanical ventilation, major surgery, and dial- ysis). In a fourth logistic regression model, TICS 27-point scores at the last HRS wave before sepsis were adjusted for to weigh the associations between presepsis cognitive function and depressive symptoms and odds of incident postsepsis cognitive impairment. As sensitivity analyses, models were fitted adjusting for TICS 35-point scores at the last HRS wave before sepsis and change in TICS 
27-point scores from two HRS waves to one HRS wave presepsis, respectively.

Two sets of sensitivity analyses were conducted to test whether follow-up timing biased the results. First, the association between presepsis substantial depressive symptoms and incident cognitive impairment at the first HRS interview after sepsis was tested. Second, whether the association between substantial presepsis depressive symptoms and incident postsepsis cognitive impairment was present even when considering participants who died during the follow-up period to be cognitively impaired was tested. Whether using different cutoff scores to define substantial depressive symptoms on the eight-item CES-D affected the results was also examined.

Similar models were used to test whether substantial presepsis depressive symptoms were associated differently with incident mild versus moderate to severe cognitive impairment separately.

Two-sided significance tests were used for all analyses with statistical significance set at $P=.05$. Analyses were performed using SPSS Statistics 18 (SPSS Inc., Chicago, IL) and Stata 11 (Stata Corp, College Station, TX).

\section{RESULTS}

From 1998 to 2005, 447 HRS respondents with normal cognitive functioning survived 540 hospitalizations for severe sepsis. Participants were followed up for up to four surveys before severe sepsis (mean 6.9 years) and up to four surveys (mean 7.0 years) afterward. Table 1 describes the 517 hospitalizations for severe sepsis $(96 \%)$ of participants who completed at least one depression assessment before their severe sepsis hospitalization.

\section{Prevalence of Presepsis Depressive Symptoms and Postsepsis Cognitive Impairment}

The prevalence of substantial depressive symptoms in participants with normal cognitive function at any HRS interview before sepsis was 38\% (95\% confidence interval $(\mathrm{CI})=34-42 \%)$. At the most immediate interview before sepsis (a median of 1.2 years before sepsis), the prevalence of substantial depressive symptoms in HRS respondents with normal cognition was $32 \%(95 \% \mathrm{CI}=23-41 \%)$.

Figure 1 shows the incidence of cognitive impairment after severe sepsis in survivors who were previously cognitively intact. In participants with normal cognitive function before sepsis, $17 \%(95 \% \mathrm{CI}=14-20 \%)$ were cognitively impaired a median of 0.9 years after severe sepsis, of whom $40 \% \quad(95 \% \quad \mathrm{CI}=30-50 \%)$ had mild cognitive impairment and $60 \%(95 \% \mathrm{CI}=50-70 \%)$ had moderate to severe cognitive impairment.

\section{Factors Associated with Postsepsis Incident Cognitive Impairment}

In unadjusted analyses, substantial presepsis depressive symptoms were associated with 2.6 times the odds $(95 \%$ $\mathrm{CI}=1.53-4.27)$ of postsepsis incident cognitive impairment. This association remained significant after sequentially adjusting for baseline characteristics, severe sepsis-related clinical characteristics, and TICS 27-point scores at the last

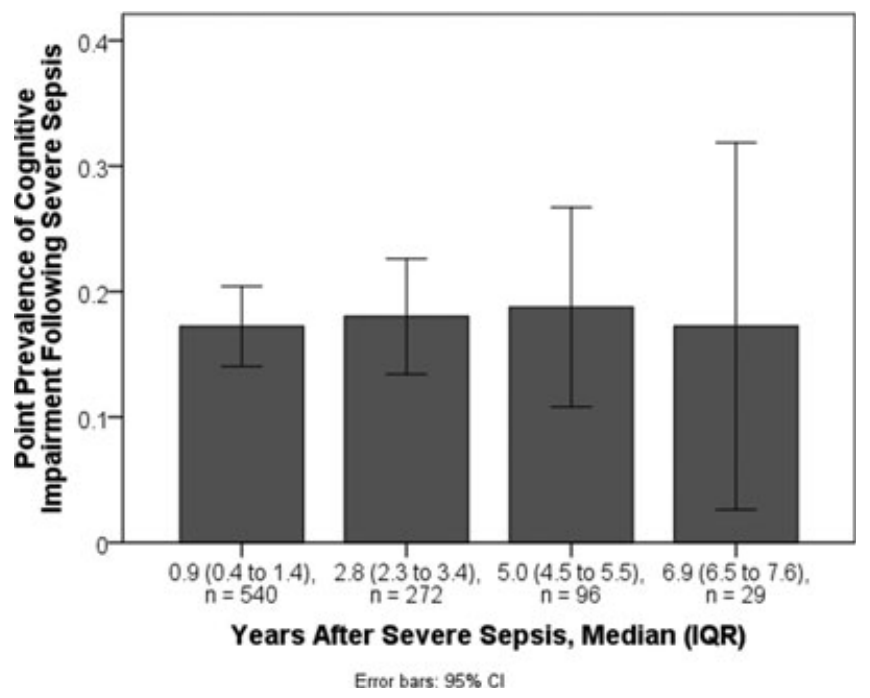

Figure 1. Point prevalence of cognitive impairment in severe sepsis survivors with normal cognition before sepsis (grouped according to timing of Health and Retirement Study (HRS) interview wave). Interpretive example: The point prevalence of cognitive impairment was $17 \%$ (95\% confidence interval $(\mathrm{CI})=14-20 \%)$ at the first HRS interview after severe sepsis.

HRS wave before sepsis $(\mathrm{OR}=2.58,95 \% \mathrm{CI}=1.45-4.59)$ (Table 2). The association between substantial presepsis depressive symptoms and incident postsepsis cognitive impairment remained significant in all of the sensitivity analyses, including models that adjusted for TICS 35-point scores at the last HRS wave before sepsis $(\mathrm{OR}=2.48,95 \%$ $\mathrm{CI}=1.38-4.45)$ and change in TICS 27-point scores from two HRS waves to one HRS wave before sepsis $(\mathrm{OR}=3.49$, 95\% CI $=1.86-6.54) \quad$ (additional data available from authors upon request).

In secondary analyses, substantial presepsis depressive symptoms were associated with 3.7 times the odds $(95 \%$ $\mathrm{CI}=1.51-8.87) \quad$ of incident postsepsis mild cognitive impairment and 2.1 times the odds $(95 \% \mathrm{CI}=1.12-3.85)$ of postsepsis incident moderate to severe cognitive impairment in the final models.

\section{DISCUSSION}

This nationwide longitudinal investigation identified that depression predating severe sepsis was independently associated with more than 2.5 times the odds of incident cognitive impairment in survivors. Because most survivors of severe sepsis with incident cognitive impairment in this cohort had moderate to severe impairment, depression in older adults before severe sepsis could increase the risk of adverse outcomes, with a profound effect in terms of caregiver burden, nursing home admissions, healthcare costs, and mortality. $1,2,4$

The present study highlights an important relationship between depression in older adults and the onset of cognitive impairment. ${ }^{10,12}$ Although observational studies like this one cannot prove causation, the existence of credible biological pathways reduces the concern that these associations are merely artifacts. One plausible causal pathway linking depression, severe sepsis, and subsequent cognitive 
Table 2. Associations Between Substantial Presepsis Depressive Symptoms and Incident Cognitive Impairment in Survivors of Severe Sepsis

\begin{tabular}{ccccc} 
Adjusted for & $\begin{array}{c}\text { Adjusted for } \\
\text { Health-Risk } \\
\text { Behaviors and } \\
\text { Comorbidity, } \\
\mathbf{n}=\mathbf{5 1 3}\end{array}$ & $\begin{array}{c}\text { Adjusted for Sepsis } \\
\text { Episode Clinical } \\
\text { Characteristics, } \\
\mathbf{n}=\mathbf{5 1 2}\end{array}$ & $\begin{array}{c}\text { Adjusted for } \\
\text { Final Presepsis } \\
\text { TICS Score, } \\
\mathbf{n}=\mathbf{5 1 2}\end{array}$ & $\mathbf{n = 4 8 0}$ \\
\hline
\end{tabular}

Odds Ratio (95\% Confidence Interval)

\begin{tabular}{|c|c|c|c|c|c|}
\hline \multicolumn{6}{|l|}{ Presepsis Participant Characteristic } \\
\hline $\begin{array}{l}\text { Substantial symptoms of depression at } \\
\text { any HRS interview before sepsis }\end{array}$ & $2.56(1.53-4.27)^{\mathrm{C}}$ & $2.86(1.68-4.88)^{\mathrm{C}}$ & $2.81(1.64-4.79)^{\mathrm{C}}$ & $2.86(1.66-4.95)^{\mathrm{C}}$ & $2.58(1.45-4.59)^{b}$ \\
\hline Age & & $1.09(1.05-1.13)^{c}$ & $1.09(1.05-1.13)^{\mathrm{c}}$ & $1.08(1.04-1.12)^{\mathrm{c}}$ & $1.05(1.01-1.09)^{\mathrm{a}}$ \\
\hline Female & & $2.61(1.48-4.60)^{c}$ & $2.24(1.24-4.05)^{\mathrm{b}}$ & $2.19(1.20-4.00)^{b}$ & $2.44(1.30-4.60)^{b}$ \\
\hline White & & $1.66(0.82-3.35)$ & $1.74(0.84-3.57)$ & $1.81(0.89-3.71)$ & $1.47(0.71-3.03)$ \\
\hline \multicolumn{6}{|l|}{ Education } \\
\hline Some college & & $0.62(0.32-1.19)$ & $0.62(0.32-1.19)$ & $0.63(0.33-1.22)$ & $0.87(0.43-1.77)$ \\
\hline College graduate & & $0.71(0.35-1.44)$ & $0.72(0.36-1.47)$ & $0.80(0.39-1.65)$ & $1.30(0.60-2.79)$ \\
\hline Single and living alone & & $0.89(0.48-1.66)$ & $0.97(0.51-1.84)$ & $0.87(0.45-1.66)$ & $0.91(0.46-1.78)$ \\
\hline Alcohol use, d/wk & & & $0.85(0.63-1.15)$ & $0.86(0.63-1.18)$ & $0.95(0.69-1.31)$ \\
\hline Current smoker & & & $0.56(0.20-1.57)$ & $0.56(0.20-1.58)$ & $0.60(0.21-1.73)$ \\
\hline Charlson comorbidity score & & & $0.90(0.75-1.09)$ & $0.94(0.78-1.15)$ & $0.88(0.72-1.07)$ \\
\hline \multicolumn{6}{|c|}{ Severe sepsis-related hospitalization characteristics } \\
\hline Organ dysfunction score & & & & $0.69(0.34-1.43)$ & $0.70(0.32-1.52)$ \\
\hline Admitted to an intensive care unit & & & & $0.83(0.47-1.44)$ & $0.81(0.44-1.52)$ \\
\hline Required mechanical ventilation & & & & $1.20(0.58-2.47)$ & $1.29(0.58-2.89)$ \\
\hline Required major surgery & & & & $0.45(0.22-0.95)^{\mathrm{a}}$ & $0.55(0.26-1.19)$ \\
\hline Required dialysis & & & & $0.15(0.01-1.60)$ & $0.19(0.03-1.24)$ \\
\hline Hospital length of stay & & & & $0.99(0.96-1.03)$ & $1.00(0.97-1.03)$ \\
\hline $\begin{array}{l}\text { TICS 27-point score at last HRS } \\
\text { wave before sepsis }\end{array}$ & & & & & $0.85(0.79-0.91)^{\mathrm{c}}$ \\
\hline
\end{tabular}

${ }^{\text {a } P}<.05$.

${ }^{\mathrm{b}} P<.01$.

${ }^{\mathrm{c}} P<.001$

HRS $=$ Health and Retirement Study; TICS $=$ Telephone Interview for Cognitive Status.

decline in older adults is through inflammation. Depression has been associated with release of proinflammatory cytokines, which it has been hypothesized leads to neurodegenerative changes in late life. ${ }^{12}$ Thus, depression could potentiate the deleterious inflammatory effect of sepsis on the brain. ${ }^{25}$ Another plausible causal pathway is through delirium. Delirium is common in older adults with sepsis, ${ }^{26}$ and delirium in critically ill individuals has been associated with subsequent long-term cognitive impairment. ${ }^{27}$ Furthermore, prior studies have found depression to be an independent risk factor for delirium during a hospitalization for medical illness in older adults. ${ }^{28,29}$ In addition, not only has depression been associated with cognitive decline in carriers of the APOE $\varepsilon 4$ allele,${ }^{13,14}$ but the presence of the APOE $\varepsilon 4$ polymorphism has also been associated with longer duration of delirium in critically ill individuals. ${ }^{30}$ That is, if, as has been hypothesized, delirium is not merely a sign of an injured brain but is a braininjuring process, then the deliriogenic effects of depression could potentiate long-term cognitive dysfunction. Further studies are needed to confirm this causal pathway, particularly because in-hospital delirium can be preventable and treatable. ${ }^{26,31}$

The possibility of a causal association raises important implications for treatment. Treatment of late-life depres- sion may improve cognitive functioning in older adults. ${ }^{32}$ Further research is needed to test the hypothesis generated here-that successful interventions for the treatment of late-life depression could reduce adverse outcomes such as cognitive impairment in older adults surviving serious medical illnesses such as severe sepsis.

An alternative interpretation for the findings could be that presepsis depression might have signified a prodrome of a dementing illness and therefore serves as a marker of impending cognitive decline rather than as a risk factor (in the physiological sense). Prior studies have reported that late-life depression, but not lifetime history of depression, is associated with risk of dementia, ${ }^{11,33}$ suggesting that depression in older adults could signify the onset of dementia. In this context, these findings could be interpreted to suggest that, in older adults, a hospitalization for a serious medical illness such as severe sepsis could serve as the insult that causes late-life depression to progress to frank cognitive decline. If true, then clinicians should monitor the cognition of older adults with a history of depression who survive severe sepsis closely to inform treatment decisions and to equip families with the information they need to maximize their loved one's quality of life.

This study has several limitations. The results primarily demonstrate long-term cognitive effects; short-term cogni- 
tive deficits (e.g., $<6-12$ months) after a hospitalization could be greater, and some participants may have had improvements in transient cognitive deficits before their next biennial HRS interview. The neuropsychological battery that was used assessed global cognitive function and could not allow measurement of individual cognitive domains, nor could it establish a clinical diagnosis of dementia, although cognitive categories and cutoff scores were used that have shown good correlation with clinical dementia as assessed by detailed neuropsychiatric interview ${ }^{34}$ and, unlike detailed neuropsychiatric assessment, are available on a populationwide basis with substantial prehospitalization prospective measurement. Because depressive symptoms were assessed using a questionnaire and not a diagnostic interview, a diagnosis of major depression could not be made. The eight-item CES-D has not been specifically validated for use before and after severe sepsis, and it lacks optimal specificity for the diagnosis of major depressive disorder. Furthermore, although it is unlikely, the possibility that participants with greater presepsis depressive symptoms could have developed symptoms of mild cognitive impairment before sepsis cannot be completely excluded. In addition, the outcome measurement could not exclude confounding by the presence of persistent postsepsis depressive symptoms, which would be optimally differentiated in a face-to-face clinical encounter. Finally, the possibility of residual confounding remains, as in any observational study.

In conclusion, substantial depressive symptoms before a hospitalization for severe sepsis are independently associated with greater odds of new cognitive impairments. Depressed older adults are at particular risk of developing cognitive impairment after a serious medical illness. Future research aimed at identifying the mechanisms that link depression, sepsis, and cognitive impairment-along with interventions that prevent or slow cognitive decline in survivors of severe sepsis-is imperative in light of the aging of the population and the enormous toll that depression and severe sepsis exact on older adults, their families and caregivers, and the healthcare system. ${ }^{9}$

\section{ACKNOWLEDGMENTS}

We appreciate the expert programming of Laetitia Shapiro and Mohammed Kabeto, University of Michigan.

The views expressed in this article are those of the authors and do not necessarily reflect the position or policy of the Department of Veterans Affairs, the National Institutes of Health, or the U.S. government.

Conflict of Interest: This work was supported by Grants KL2 RR025015-05, K08 HL091249, R01 AG030155, and U01 AG09740 from the National Institutes of Health. HRS is performed at the Institute for Social Research, University of Michigan.

Author Contributions: All authors: study concept and design, analysis and interpretation of data, and drafting and revising of manuscript. Dr. Davydow had full access to all the data in the study and takes responsibility for the integrity of the data and the accuracy of the data analysis.

Sponsor's Role: The sponsor had no role in the design, methods, subject recruitment, data collection, analysis, or preparation of the manuscript.

\section{REFERENCES}

1. Guehne U, Riedel-Heller S, Angermeyer MC. Mortality in dementia. Neuroepidemiology 2005;25:153-162.

2. Kinosian BP, Stallard E, Lee JH et al. Predicting 10-year care requirements for older people with suspected Alzheimer's disease. J Am Geriatr Soc 2000;48:631-638.

3. Iwashyna TJ, Ely EW, Smith DM et al. Long-term cognitive impairment and functional disability among survivors of severe sepsis. JAMA 2010;304:1787-1794.

4. Langa KM, Chernew ME, Kabeto MU et al. National estimates of the quantity and cost of informal caregiving for the elderly with dementia. J Gen Intern Med 2001;16:770-778.

5. Iwashyna TJ. Survivorship will be the defining challenge of critical care in the 21st century. Ann Intern Med 2010;153:204-205.

6. Ehlenbach WJ, Hough CL, Crane PK et al. Association between acute care and critical illness hospitalization and cognitive function in older adults. JAMA 2010;303:763-770.

7. Milbrandt EB, Eldadah B, Nayfield S et al. Toward an integrated research agenda for critical illness in aging. Am J Respir Crit Care Med 2010;182:995-1003.

8. Angus DC, Linde-Zwirble WT, Lidicker J et al. Epidemiology of severe sepsis in the United States: Analysis of incidence, outcome, and associated costs of care. Crit Care Med 2001;29:1303-1310.

9. Iwashyna TJ, Cooke CR, Wunsch $\mathrm{H}$ et al. The population burden of longterm survivorship after severe sepsis among older Americans. J Am Geriatr Soc 2012;60:1070-1077.

10. Ownby RL, Crocco E, Acevedo A et al. Depression and risk for Alzheimer's disease: Systematic review, meta-analysis, and metaregression analysis. Arch Gen Psychiatry 2006;63:530-538.

11. Li G, Wang LY, Shofer JB et al. Temporal relationship between depression and dementia: Findings from a large community-based 15-year follow-up study. Arch Gen Psychiatry 2011;68:970-977.

12. Katon WJ, Lin EHB, Williams LH et al. Comorbid depression is associated with an increased risk of dementia diagnosis in patients with diabetes: A prospective cohort study. J Gen Intern Med 2010;25: $423-429$.

13. Irie F, Masaki KH, Petrovitch $\mathrm{H}$ et al. Apolipoprotein $\varepsilon 4$ allele genotype and the effect of depressive symptoms on the risk of dementia in men: The Honolulu-Asia Aging Study. Arch Gen Psychiatry 2008;65: 906-912.

14. Corsentino EA, Sawyer K, Sachs-Ericsson N et al. Depressive symptoms moderate the influence of the apolipoproteine epsilon 4 allele on cognitive decline in a sample of community dwelling older adults. Am J Geriatr Psychiatry 2009;17:155-165.

15. Opal SM, Girard TD, Ely EW. The immunopathogenesis of sepsis in elderly patients. Clin Infect Dis 2005;41:S504-S512.

16. Charlson ME, Pompei P, Ales KL. A new method for classifying prognostic comorbidity in longitudinal studies: Development and validation. J Chronic Dis $1987 ; 40: 373-383$.

17. Levy MM, Fink MP, Marshall JC et al. Crit Care Med 2003;31:12501256.

18. Iwashyna TJ, Odden A, Rohde J et al. Identifying patients with severe sepsis using administrative claims: Patient-level validation of the Angus implementation of the International Consensus Conference Definition of Severe Sepsis. Med Care in press.

19. Radloff LS. The CES-D Scale: A self-report depression scale for research in the general population. Appl Psychol Measurement 1977;1:385-401.

20. Soldo BJ, Hurd MD, Rodgers WL et al. Asset and health dynamics of the oldest old: An overview of the AHEAD study. J Gerontol B Psychol Soc Sci 1997;52B:1-20.

21. Kohout FJ, Berkman LF, Evans DA et al. Two shorter forms of the CES-D (Center for Epidemiological Studies Depression) depression symptoms index. J Aging Health 1993;5:179-183.

22. Steffick D. Documentation of Affective Functioning Measures in the Health and Retirement Study. Ann Arbor, MI: Survey Research Center, 2000.

23. Langa KM, Larson EB, Karlawish JH et al. Trends in the prevalence and mortality of cognitive impairment in the United States: Is there evidence of a compression of cognitive morbidity? Alzheimers Dement 2008;4: $134-144$.

24. Huber PJ. Robust Statistics. New York: Wiley, 1981.

25. Jacob A, Brorson JR, Alexander JJ. Septic encephalopathy: Inflammation in man and mouse. Neurochem Int 2011;58:472-476.

26. Sprung CL, Peduzzi PN, Shatney $\mathrm{CH}$ et al. The Veterans Administration Systemic Sepsis Cooperative Study Group. Impact of encephalopathy on mortality in the sepsis syndrome. Crit Care Med 1990;18:801-806. 
27. Girard TD, Jackson JC, Pandharipande PP et al. Delirium as a predictor of long-term cognitive impairment in survivors of critical illness. Crit Care Med 2010;38:1513-1520.

28. Pompei P, Foreman M, Rudberg $\mathrm{M}$ et al. Delirium in hospitalized older persons: Outcomes and predictors. J Am Geriatr Soc 1994;42:809_ 815 .

29. McAvay GJ, Van Ness PH, Bogardus ST et al. Depressive symptoms and the risk of incident delirium in older hospitalized adults. J Am Geriatr Soc 2007;55:684-691.

30. Ely EW, Girard TD, Shintani AK et al. Apolipoprotein E4 polymorphism as a genetic predisposition to delirium in critically ill patients. Crit Care Med 2007;35:112-117.
31. Ely EW, Shintani A, Truman B et al. Delirium as a predictor of mortality in mechanically ventilated patients in the intensive care unit. JAMA 2004;291:1753-1762.

32. Butters MA, Becker JT, Nebes RD et al. Changes in cognitive functioning following treatment of late-life depression. Am J Psychiatry 2000;157:1949-1954.

33. Fuhrer R, Dufouil C, Dartiques JF et al. Exploring sex differences in the relationship between depressive symptoms and dementia incidence: Prospective results from the PAQUID Study. J Am Geriatr Soc 2003;51: 1055-1063.

34. Plassman BL, Langa KM, Fisher GG et al. Prevalence of dementia in the United States: The Aging, Demographics, and Memory Study. Neuroepidemiology 2007;29:125-132. 